\title{
Amina Bin Qarrish de Tetuan: registros da vida de uma mulher marroquina do século XIX*
}

\author{
Nadia Erzijni**
}

\begin{abstract}
Resumo
Este artigo registra a tentativa de escrever a biografia de uma mulher de Tetuan do século XIX, Amina Bin Qarrish (morta em 1889), esposa de 'Abdalkrim ar-Razini (morto em 1909). Ela foi uma mulher rica, o último membro sobrevivente da família de Zawiyat Ben Qarrish, uma comunidade Sufi fundada em Tetuan no final do século XVII ou início do século XVIII. As principais fontes para esta biografia são uma coleção de documentos inéditos (documentos legais, cartas e anotações em cadernos) do arquivo Razini em Tetuan. Esses documentos tratam de herança, casamento, divórcio, propriedade, procurações, presentes, awqaf, experiências de guerra e da vida familiar de Amina Bin Qarrish e de mulheres contemporâneas. Também é possível usar a história oral para auxiliar a interpretar esses documentos.
\end{abstract}

Palavras-Chave: Amina Bin Qarrish, Mulheres Marroquinas, Herança, Século XIX.

\footnotetext{
* Recebido para publicação em dezembro de 2007, aceito em abril de 2008 [Tradução: Silvana Ruffier Scarinci].

** Consultora do Ministério de Assuntos Islâmicos e Awqaf no Marrocos, historiadora e historiadora da arte do Marrocos. http://iea:um5s:ac.ma
}

cadernos pagu (30), janeiro-junho de 2008:43-52. 
Uma mulher marroquina do século XIX

Amina Bin Qarrish of Tetuan:

Records of the Life of a Moroccan Woman of the $19^{\text {th }}$ Century

\begin{abstract}
This article records the attempt to write a biography of a woman of $19^{\text {th }}$ century Tetuan, Amina Bin Qarrish (d.1889), wife of 'Abdalkrim ar-Razini (d.1909). She was a wealthy woman, the last surviving member of the family of the Zawiyat Ben Qarrish, a Sufi fraternity founded in Tetuan in the late $17^{\text {th }}$ or early $18^{\text {th }}$ century. The principal sources for the biography are a small collection of unpublished documents (legal documents, letters and jottings in notebooks) in the Razini archive in Tetuan. These documents deal with the inheritance, marriage, divorce, property, power of attorney, gifts, awqaf, experience of war, and family life of Amina Bin Qarrish, and those of contemporary women. It is also possible to use oral history to help interpret these documents.
\end{abstract}

Key words: Amina Bin Qarrish, Inheritance, Moroccan Women, $19^{\text {th }}$ Century. 
O arquivo $^{1}$ da família de ar-Razini de Tetuan reúne uma coleção de correspondência comercial e documentos legais relacionados a negócios e propriedade, produzidos por tabeliões para as famílias influentes, proprietárias de terra de Tetuan, quase todas datando do final do século XVIII e início do século XIX. Previsivelmente, preservaram-se, no arquivo, documentos que se referem a mulheres (livres, escravas e mulheres libertadas), especialmente contratos de casamento (sdaqat) e partilhas de heranças (iratat), uma vez que as mulheres herdam em conjunto com os homens. Fiquei surpresa ao descobrir as mulheres como as principais $e$ as mais significativas personagens nos documentos relativos aos testamentos (wasiyat), presentes (hibat) e certificados nomeando representantes ou passando procurações (niyabat $e$ wikalat). Neste último tipo de documento, as mulheres indicavam representantes e elas mesmas eram indicadas como representantes para seus maridos e filhos. Fiquei ainda mais surpresa ao descobrir alguns documentos no arquivo Razini, referindo-se especificamente ao status legal das mulheres em atividades comerciais e em negócios com propriedades. Esses documentos incluem contratos de comércio internacional (sharikat al-qirad), nos quais as mulheres são sócias investidoras; atestados (shahadat) sobre propriedades pessoais das mulheres, diferenciando-se da propriedade de seus maridos e de seus coherdeiros da família do marido; e declarações de maioridade (rushdiyyat) das mulheres, permitindo-lhes tomar conta de suas próprias ocupações financeiras. Além disto, encontrei cartas escritas por mulheres a seus maridos e a seus pais, e cartas escritas

1 O arquivo de ar-Razini reúne uma coleção de cerca de 30.000 documentos históricos e 200 livros de contabilidade que foram preservados na casa da família em Tetuan. Em 2000, a Fundação Max van Berchem financiou a catalogação deste arquivo. A Max van Berchem Foundation é uma fundação científica estabelecida em Genebra, Suiça, em memória de Max van Berchem (18631921), fundador da epigrafia árabe. Ela busca promover o estudo da arqueologia, história, arte, epigrafia, religião e literatura. Sobre o arquivo arRazini, ver Erzijni, 2002. 
Uma mulher marroquina do século XIX

para mulheres. Esses documentos são complementados por breves menções às mulheres nas cartas dos homens e em seus livros de contabilidade.

Evidentemente, essas mulheres tiveram pouca ou nenhuma participação na vida pública da cidade de Tetuan; suas vidas eram estritamente controladas por hábitos de segregação de gênero $e$ em seus papéis como esposas e mães. De fato, as famílias mais ricas podiam exercer um maior grau de segregação. No entanto, ao contrário do estereótipo da mulher oriental, submissa e à sombra do homem, a pintura que emerge dos documentos do arquivo Razini sugere a presença de fortes personalidades individualizadas e histórias de vida complexas e variadas. Dentre as mulheres do século XIX de Tetuan, que aparecem nos documentos do arquivo Razini, uma mulher se sobressai mais do que suas contemporâneas. Seu nome é mencionado num total de cerca de 20 documentos, e por essa razão a escolhi como sujeito desta biografia, talvez a primeira biografia detalhada de uma mulher do século XIX no Marrocos. Amina bint Ahmad bin 'Abdalghafur bin 'Abdasalam Bin Qarrish, falecida em 1889, era esposa de 'Abdalkrim bin Ahmad bin Hassan bin Qasim ar-Razini, que morreu em 1909. Esta mulher também aparece, embora anonimamente, nas histórias de Tetuan escritas por Dawud (Tarikh Titwan) e Rahuni (Umdat Rawiyyin), como último membro sobrevivente da família de Bin Qarrish zawiya. Eles eram contemporâneos de Rahuni, e Dawud publicou vários documentos referindo-se à herança de Bin Qarrish. Sua filha 'Alia' ar-Razini casou-se com seu primo Abdalqadir ar-Razini, meu bisavô (morto em 1928), por isso alguns documentos da família Bin Qarrish sobrevivem no arquivo Erzini.

Como mencionei, Amina Bin Qarrish foi o último membro sobrevivente da família sharifi do Zawiyat Bin Qarrish, uma comunidade Sufi, cujo centro se estabelecera num prédio localizado na Rua Watya do bairro Uyun de Tetuan. Os membros da família Bin Qarrish eram conhecidos como estudiosos e proprietários de terras no século XVII na vila de Dar Bin Qarrish 
em Bani Hozmar e, nesta época, também se fixaram em Tetuan. A comunidade Zawiya ganhou importância no século XVIII, e três gerações da família Bin Qarrish foram indicadas juízes principais de Tetuan no século XVIII: Mhammad (sic) bin Qasim; Muhammad bin Mhammad (sic); e 'Abdasalam bin Muhammad (morto em 1792-93). Este último, Qadi 'Abdasalam Bin Qarrish, foi bisavô de Amina. No final do século XVIII, Zawiyat Bin Qarrish adquiriu um número considerável de propriedades como awqaf (ou fundo de caridade vitalícia). A propriedade do awqaf pertencente às zawiyas era, como sempre, dividida em duas partes, o awqaf público pertencente à zawiya, administrada pela família zawiya, e o awqaf particular ou da família, para prevenir a dispersão das propriedades familiares pelas leis de herança islâmicas e para proteger os membros pobres ou destituídos da família.

Analogamente, em seu leito de morte, entre 1792 e 93, o Qadi 'Abdasalam escreveu um testamento sobre um terço de suas propriedades (wasiyat ath-thuluth), deixando sua residência principal - Dar al-Kubra, ou Dar al-Faqih Bin Qarrish no Watya, como ainda hoje é conhecida - e outras propriedades para os netos de seu filho, 'Abdalghafur - aos netos nascidos e aqueles que ainda não tinham nascido. Se esses netos morressem, as propriedades iriam para as filhas e as netas de Qadi 'Abdasalam (awlad al-banat min dhuriyatihi). Se todos eles morressem, essas propriedades iriam para o awqaf do zawiya. E realmente foi isso que aconteceu: primeiramente, o herdeiro Bin Qarrish morreu, e depois as mulheres e o wasiya ath-thuluth do Qadi 'Abdasalam transformou Amina Bin Qarrish numa mulher muito rica. Além disso, seu tio Muhammad Bin Qarrish morreu em 1834, deixando à jovem menina (shabba), Amina, outro wasiya, liberando-a de quaisquer dívidas em relação a sua manutenção (nafaqa). O wasiyat ath-thuluth de Qadi Abdasalam foi uma forma de doação bastante comum entre as famílias abastadass de Tetuan, mas freqüentemente resultava em disputa sobre quem deveria ser herdeiro e quando poderiam solicitar a herança. Amina entraria 
Uma mulher marroquina do século XIX

numa disputa com sua tia-avó, Fama bint 'Abadasalam Bin Qarrish, até 1870, e sobre essa disputa existem diversos documentos e fatawi que sobreviveram. Amina finalmente pôde esclarecer as questões sobre seu direito à herança, mas como mulher, ela não poderia administrar as propriedades diretamente. Incidentalmente, Fama bint 'Abdasalam Bin Qarrish oferece um insight sobre o tipo de família zawiya na qual Amina nasceu. Ela é descrita nos documentos como a sábia religiosa (faqiha) Fama e parte da disputa envolvia a "Dar al-faqihat" ao lado da casa de Qadi "Abdasalam no Watya. Seria esta uma residência especialmente para as mulheres dessa família, ou era uma espécie de instituição educacional para mulheres? Fama parece ter tido pelo menos três maridos e ter se envolvido em numerosos casos em tribunais tratando de propriedade.

Dos documentos do arquivo Razini podemos também reconstruir a linhagem maternal de Amina Bin Qarrish. Sua mãe chamava-se Fatima bint 'Abdalmalik Amahli, outra família que desde então desaparecera em Tetuan. Ela era descendente do santo e majdub Sidi Bujida Amahli, cujo túmulo se localiza em Gharsa Kabira. O pai de Amina era casado com Akhdij ou Khadija bint 'Abdasalam Rakaina, um importante comerciante de sua época. Ao desembaraçar a trama bizantina de relações que caracteriza as famílias históricas de Tetuan, descobrimos que Amina e seu marido 'Abdalkarim ar-Razini eram, de fato, primos bastante próximos, através da ligação com Rakaina. Uma vez que o pai e os parentes homens morreram quando ela era jovem, ela parece ter crescido na casa Razini, um prédio construído no final do século XVIII, em Farran Msilless, cerca da Grande Mesquita, e reformada no século XIX. Cartas de "Abdalkarim antes de seu casamento referem-se a "khalti de Bin Qarrish", o que implica na existência de uma tia casada com os Bin Qarrish, morando na casa Razini.

Em 1842, Amina Bin Qarrish estava casada com o comerciante 'Abdalkarim ar-Razini e o contrato de casamento merece uma leitura cuidadosa. Por exemplo, o documento refere- 
se a ela com elogios típicos para uma mulher virtuosa e reservada (al-mawsuna ou al-asina), tratando-a de pérola-preciosa (ad-durra ath-thamina) e, especificamente, como uma mulher solteira ou virgem (adhra'), tendo atingido a idade da puberdade (balighat sinniha). Seu presente de casamento é o impulso inicial típico das famílias abastadas do século XVIII e XIX em Tetuan: qaftans de brocado, alfombras de seda e uma escrava. Ainda mais interessante é o fato de que, ao contrário da proposta e presente de casamento serem aceitos por seu pai, mãe ou algum parente masculino, é a própria Amina que aceita a proposta de casamento e aprova o presente.

'Abdalkarim era o irmão mais jovem de Muhammad e Ahmad ar-Razini, alguns dos comerciantes mais influentes de meados do século XIX no Marrocos. Muhammad era também cônsul in Gibraltar e Ahmad era administrador financeiro (amin alumana') no porto de Tânger. Abdalkarim era, ele próprio, amin em Essaouira (1859) e Melilla (1872-73). Ele também vivera em Mashriq, Fes e Gibraltar em função dos negócios da família por muitos anos durante seu casamento, acompanhado não por sua esposa, mas, como era tradicional, por uma escrava (branca) (Mbirika) com quem ele tinha dois filhos. Quando os homens encontravam-se longe de casa, a vida doméstica era deixada a cargo de suas mães, uma figura matriarcal que aparece organizando diversos casamentos, 'Alia' Rakaina. Em segundo lugar na hierarquia das mulheres encontrava-se a esposa do irmão mais velho, Muhammad, Um Kulthum Hassar, e sua posição como esposa mais velha recebia o título "lalla al-'arusa", tradicional em Tetuan até o início do século XX.

Conhecemos a vida de Amina com detalhes pouco usuais durante um período de mais de dezesseis anos ela teve seis filhos e um aborto natural. Seu marido anotou cuidadosamente que ela perdera um menino. Somente três de seus filhos sobreviveram à infância, um deles provavelmente morreu de varíola (jidri) e outro de cólera no Haj. Uma filha sobreviveu a certa doença tornandose surda-muda para o resto da vida. 
Uma mulher marroquina do século XIX

Amina parece não ter escrito suas próprias cartas, mas sua cunhada, Khadija ar-Razini, esposa de Ahmad ar-Razini teve a incumbência de escrever todas as cartas das outras mulheres da casa. Algumas cartas de 1840 mencionam crianças doentes durante a epidemia de varíola. Cerca de cinco cartas dirigidas a "ahl ad-dar" ele envia cumprimentos a todos, inclusive às escravas e amigas, expressa suas saudades, elogia seus filhos com Mbirika, a escrava, desculpa-se com sua mulher Amina, refere-se aos nascimentos e mortes, às compras e solicita comida caseira, como um pote de carne defumada (qadra d'al khli ${ }^{\circ}$ ). Enquanto as cartas dos homens são escritas numa mistura de árabe clássico e dialeto, as cartas das mulheres são muito pouco usuais, numa letra infantil, cobertas de erros de ortografia e expressóes dialéticas: jidri bizzaf... daba hum shwiwish... twahashnak... aji daghya... kan tanawwak (tem muita varíola... elas estão melhores agora... sentimos sua falta... volte logo... estamos a sua espera).

As cartas familiares se referem às disputas entre as muitas mulheres dos parentes próximos de Razini e aos problemas entre Amina e uma escrava. Em uma das cartas, a sogra de Amina trata-a com termos extremamente rudes, acusando-a de dominar seu marido, de caluniar a família, de bruxaria e de enfeitiçar os homens (sihr). Amina e 'Abdalkarim mudaram-se da casa arRazini para uma casa própria, perto de Zawiya de Sidi Yusuf Ahansal em Tetuan. A segunda metade do casamento de Amina e 'Abdalkrim' parece atormentada por brigas entre os dois. 'Abdalkarim administrava as propriedades do Bin Qarrish, os aluguéis residenciais $e$ as terras plantadas, e havia disputas sobre a renda. Ela também emprestou dinheiro para seu marido, possivelmente como sharikat al-qirad para negócios, mas ele não lhe devolveu. Quando o marido viajou para o exterior, ela fez questão de documentar nos tabeliões o que era sua propriedade pertencente a seu dote (sunduq nisawi) na casa ar-Razini, especialmente sua notável coleção de jóias de ouro com diamante, etc. Finalmente, Amina forçou seu marido a fazer um juramento público (half b'al-yamin) para provar sua inocência 
diante de um juiz, um evento humilhante de todos os pontos de vista. Essas brigas culminaram em seu divórcio, em 1852-53, e em novos matrimônios de ambas as partes. O documento de divórcio declara que a razão para tal deu-se em função de 'Abdalkarim não cumprir os acordos estipulados por sua mulher. Como o historiador Dawud declarou em sua história de Tetuan, divórcio e poligamia eram raros na cidade no século XIX. A relação entre as famílias do casal obrigava os homens a respeitarem, de certa forma, suas mulheres.

Uma notável lacuna em nossa apreensão da vida tanto de homens quanto de mulheres em Tetuan no século XIX é o período da guerra de 1860, durante a ocupação da cidade pelos espanhóis e a evacuação de todas as famílias muçulmanas para outras cidades. A partir de referências fragmentadas podemos deduzir que Amina e algumas outras mulheres da casa Razini fugiram primeiramente para as altas montanhas de Bani Yiddir, de lá para Chaouen e depois para Tânger, e ao menos uma jovem morreu na época da evacuação, ou pouco depois. Para mulheres segregadas desta forma, o evento deve ter sido um enorme transtorno, sobre o qual a história é quase totalmente silenciosa.

Para ajudar na reconstrução da vida de Amina, através da história oral, falei com uma mulher da família de quase 90 anos, outra bisneta de Amina Bin Qarrish. Esta senhora me informou que Amina Bin Qarrish tinha uma reputação terrível - "qabiha, 'afrita, kat 'amal al-msayyib n'ar-rijal". Aparentemente, Amina era cruel com as escravas em sua casa e sua atitude é contrastante com o comportamento casto e piedoso de outras mulheres da família. No entanto, fica pouco claro em que extensão Amina era uma mulher difícil e polêmica, ou se ela era apenas uma mulher rica de família influente, simplesmente defendendo seus direitos legais e sua propriedade.

Esses documentos preservados, quase que por acaso, apontam um quadro inevitavelmente fragmentado $e$ incompleto. Precisamos nos dar por satisfeitos com a pouca evidência e muita especulação. No entanto, esses documentos raros são a única 
Uma mulher marroquina do século XIX

chance de escutar essas "vozes" de mulheres e reconstruir as particularidades de suas vidas, numa região onde a história é predominantemente sobre os homens e sua vida pública.

\section{Referência bibliográfica}

ERZIJNI, Nadia. British Moroccan relations in the first half of the 19th century, from the perspective of the Erzani archive. In: TEMIMI, A. and OMRI, M. S. (eds.) La Grande Bretagne et le Maghreb: Etat de recherches et contacts culturels. Zaghouan, 2002, pp.85-95. 